\title{
Measuring which support systems really work to improve students learning in your class - A case study on quantitative methods courses in the social sciences
}

\author{
Dimitri Prandner1, ${ }^{1}$, Ahmed Tabakobic ${ }^{2}$ \\ ${ }^{1}$ Empirical Social Research Unit, Johannes Kepler University Linz, Austria, ${ }^{2}$ Department of \\ Communication Studies, Paris Lodron University Salzburg, Austria
}

\begin{abstract}
While the so-called "datafication of society" increased the societal relevance of quantitative data analysis, social science students - who should use such data to understand and explain society - are often skeptical towards quantitative methods and overwhelmed by it.

Thus, universities around the world should find means to help their students improve their corresponding analytical skills.

The paper uses a case study from the University of Salzburg - Austria - to illustrate which aspects actually improve student-learning outcomes in the field of quantitative methods. The researched aspects focus on the program and institutional levels and address two specific issues: The evaluation and feedback on student performance and the introduction of additional support structures.

While homework and feedback still show the best results additional technology based - approaches like video-tutorials have a significant impact on student performance.
\end{abstract}

Keywords: Datafication; Video Tutorials; Student Feedback; Quantitative Methods; Social Sciences Statistics. 


\section{Introduction - Two competing worlds}

The Adult Skills survey of the Organization for Economic Co-operation and Development demonstrates that one in seven workers worldwide uses advanced mathematics and statistics in their profession (OECD, 2016). A number that will most likely grow in the future, as the so-called "datafication of society" (Lycett, 2013, 383) - based on the rapid expansion of digital communication technology - led to a seemingly endless stream of quantitative data. This also results in the necessity to discuss further associated social implications (Couldry \& Mejias, 2018). On a daily basis the media, politicians, teachers, and friends, use data to illustrate their arguments. At the same time the tools that shape this "datafication" - be it comments and posts on Internet blogs, social media etc. - reveal that a significant number of individuals has difficulties to distinguish between opinions and factual data (Nardi, 2018), resulting in a broad skepticism regarding the general reliability and validity of quantitative information.

Consequently, teaching quantitative methodology in higher education, especially in the field of social sciences, becomes more important than ever. Disciplines like sociology, political science, communication studies etc. train students to understand and analyze society. Alumni of these programs need to understand both potentials and limits of data. They must be able to judge data quality and provide meaningful interpretations. Yet, past studies show a negative bias of social science students when it comes to statistics and quantitative methods (Zeidner, 1991; Carter et al., 2017). Therefore, two competing narratives exist: While the relevance of quantitative data to society increases, the group of individuals that should use it to understand and explain society is skeptical towards quantitative methods. Thus, universities around the world should look at the quantitative methodology courses in their social science curricula and find means to help their students improve the corresponding analytical skills. This paper tackles those issues in particular. Section 2 discusses potential strategies to improve students' success. Section 3 introduces a case study from the University of Salzburg (Austria), before a discussion and the results follow the paper. However we argue that the methods we applied to test student support systems and their outcome is of general interest and does not only account for quantitative methods courses.

\section{Theoretical implications and the selected case study}

The paper tests to what extent are different strategies, which are proposed by recent literature, improving student-learning outcomes. The researched aspects focus on the program and institutional levels, addressing two specific issues: The evaluation and feedback on student performance and the introduction of additional support structures.

The first part covers traditional student evaluation and team orientated practices that may help students improve their knowledge over the duration of a semester. As quantitative 
methodology is seen as a challenge by students, team based learning provides a potential solution. Teaming-up to solve problems, sharing gained knowledge and working collaboratively should improve learning outcomes via peer-feedback and support (Michaelsen \& Sweet, 2008). As methods-classes often require students to follow complex examples and explanations during class, time available for in class assignments is short. Homework provides the opportunity to compensate for this, as students can engage with the material on their own, and the lecturer can individualize feedback. The most comprehensive meta-analyses dealing with the effects of homework - done by Cooper (1989) and her colleagues (Cooper et al. 2006) - cover the period between the 1930ties and 2003, illustrate that there is a general positive, statistically significant correlation between the amount of homework and learning outcomes (Cooper et al., 2006, p. 48). This also extends to the chance for students to resubmit work after receiving feedback on their assignments as well. However, to implement those procedures properly, lecturers need to manage groups, develop suitable tasks that help individuals or groups to improve and give feedback (Michaelsen \& Sweet, 2008).

To cover the second aspect - additional support structures - research indicates that lecturers often report students entering their classes with a deficit in the math skills, which would be needed for succeeding the course (Baharun \& Porter, 2012; Kay \& Kletskin, 2012; Winch \& Cahn, 2015). Thus, it seems sensible that quantitative methods courses could benefit from tools that would establish a more uniform knowledge, preferably without effecting the time allotted to new content (Winch \& Cahn, 2015). Different solutions to this can be found in existing literature (Ayres 2006; Mayer et al. 2002), including: (1) the introduction of supplemental material, e.g. extensive manuals explaining statistical procedures. (2) The reorganizing of the material into smaller parts so students can learn incrementally, e.g. splitting material in different subchapters that students can digest in shorter timeframes. (3) Offering individualized feedback and discussion of problems with the material, e.g. using a student assistant to explaining tasks that are necessary for class in extra tutorial units.

Technological advancements and the prevalence of social media made it possible to provide such structures not only via written scripts (manuals) or tutorial units, offered by student assistants, but also via pre-made tutorial videos. They are a potential tool to address some of the difficulties found in teaching quantitative methods, especially when used to supplement and not to replace a lecture (Kay \& Kletskin, 2012). They allow students to portion the material, fitting their learning regime, repeat or skip parts as necessary and directly demonstrate the steps necessary to complete the task. Yet, it takes considerable time and planning to produce them and implement them within the framework of a lecture or course.

Additionally, individual students may show different levels of academic engagement understood as the "quality of effort students devote to educationally focused activities that contribute directly to desired outcomes” (Kuh \& Hu, 2001). While it is a robust predictor for 
learning outcomes, it is multi-dimensional; involving students' emotion, behavior, and cognition (Finn \& Zimmer, 2012). Thus, it lies outside the scope of this paper, which deals with program based initiatives.

\subsection{The presented case study - The Seminar Quantitative Methods in Communication Studies}

Building upon the previous assumptions, the case example of this paper will discuss the seminar on quantitative methods in communication studies from the University of Salzburg. Officially, part of the fourth semester in the BA-program, the class grants students 4 credits according to the ECTS regulations (Workload: 100 hours). Students are expected to have completed an introduction lecture on empirical social sciences as well statistics before.

The main task of the course is to introduce students to uni- and bi-variate data analysis via a statistics software package - SPSS -, teach them how to design as well as field a small-scale survey. The curricular requirements for completing the class are a written exam, testing their knowledge regarding statistical procedures, as well as a final paper, presenting the results of their own survey. There is no adjustment of grades based on class performance; e.g. there is no grading on a curve. The absolute score is assigned a numeric grade: 1 - very good (Scores 91-100\%), 2 - good (Scores: 81-90\%), 3 - satisfactory (Scores: 67-80\%), 4 - sufficient (Scores: 51-66\%) as well as 5 -failed (Scores: 0-50\%).

Despite the fact that content and the corresponding guidelines are comparable to other social science methods classes in Austria, seminar lecturers were confronted with students claiming that they are overwhelmed. This sentiment effected course evaluation as well: It was consistently scored lower than others in the program. At the same time, the responsible lecturers were not satisfied with the learning outcomes of the students, as they should prepare students for social scientific work (Prandner \& Moosbrugger, 2018). Thus, it was decided to test different ways to improve student performance and overall satisfaction with the course.

\section{Data and Hypothesis}

The presented data was collected by the module coordinator for empirical research methods at the department of communication studies at the University of Salzburg, limiting the valid cases to 147 students, taking the class between 2014 and 2018. However, it increases the comparability as well as the consistency of the measurements, as other lecturers were not part of the faculty and thus rotated from year to year. To test which of the initiatives improve the learning outcome - measured in the form of standardized grades and thus a limitation of this project - different arrangements of feedback based and support structures based initiatives were tested over the courses in five years (overview: Table 1). The reason why different measurers were tested each year ties to financial and staff limitations. E.g. the production of 
extensive supporting materials - in 2015 a manual with 150 pages covering the course content was written by two lecturers - tied up resources that were not available otherwise. Student assistants had to be used strategically as well, as e.g. group tutorials take away time that may be used for grading papers or tests in other semesters.

Table 1. Structural info on the researched courses.

\begin{tabular}{|c|c|c|c|c|c|c|c|}
\hline Info & $\underset{\sim}{\mathbb{D}}$ & 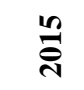 & $\stackrel{\bullet}{\stackrel{1}{2}}$ & ลิ & $\stackrel{\infty}{\stackrel{\sim}{\sim}}$ & 흉 & $\begin{array}{l}\text { Exp. } \\
\text { Effect }\end{array}$ \\
\hline Number of Students (N; multiple values & 28 & 18 & 21 & 14 & 11 & 147 & \\
\hline indicate multiple groups) & & +22 & & +19 & +14 & & \\
\hline$\%$ of Female Students & $68 \%$ & $75 \%$ & $62 \%$ & $64 \%$ & $64 \%$ & $67 \%$ & \\
\hline $\begin{array}{l}\text { Grade (Final; } 1 \text { „,very good“ to } 5 \\
\text { „failed“); Mean (std. Dev.) }\end{array}$ & $\begin{array}{l}2.04 \\
(0.8)\end{array}$ & $\begin{array}{l}1.98 \\
(1.1)\end{array}$ & $\begin{array}{l}2.19 \\
(0.8)\end{array}$ & $\begin{array}{l}2.64 \\
(0.9)\end{array}$ & $\begin{array}{l}3.12 \\
(1.2)\end{array}$ & $\begin{array}{l}2.37 \\
(1.1)\end{array}$ & \\
\hline $\begin{array}{l}\text { Grade (Exam; } 1 \text { „very good“ to } 5 \\
\text { „failed“); Mean (std. Dev.) }\end{array}$ & $\begin{array}{l}2.08 \\
(1.1)\end{array}$ & $\begin{array}{l}1.93 \\
(1.2)\end{array}$ & $\begin{array}{l}2.71 \\
(1.0)\end{array}$ & $\begin{array}{l}2.00 \\
(0.9)\end{array}$ & $\begin{array}{l}3.24 \\
(1.2)\end{array}$ & $\begin{array}{l}2.31 \\
(1.2)\end{array}$ & \\
\hline Group Tutorials & No & Yes & Yes & No & Yes & & + \\
\hline Ext. Supporting Material - “manual” & No & No & Yes & Yes & Yes & & + \\
\hline Video Tutorials & No & No & Yes & Yes & No & & + \\
\hline Individual papers (no group learning) & Yes & No & No & Yes & No & & - \\
\hline Resubmitting of final paper - "Redo" & Yes & Yes & Yes & No & No & & + \\
\hline Homework incl. feedback & Yes & Yes & Yes & Yes & No & & + \\
\hline
\end{tabular}

Source: Own depiction (2019).

To improve student performance, the aforementioned manual was produced which covered the core course content and followed the layout of the course - including supporting material they could use during one's own survey project, layouts for statistical tests and examples for their application, visualization and interpretation of results, as well as a guide for SPSS use. Additionally eight videos - each approximately 20 Minutes - were produced covering SPSS usage, made available via the department's online platform. However, the resources necessary to update them were not available. Thus, they were not used in 2018. Those initiatives were in some years accompanied by group based learning initiatives that helped students write their final paper in groups of 3 to 5 members. When it comes to feedbackbased initiatives group tutorials were offered. Student assistants provided feedback, discussed examples not covered in class and individual problems. Additionally it was tested, if written homework, which got individualized feedback, could improve performance. It 
consisted of five different statistical problems and affected the final grade. The last initiative was the chance to resubmit a paper, which would have resulted in failing the class, and adjust the paper based on feedback of the lecturer.

All of these initiatives were included in a path model that uses linear regression (see figure 1); aiming to explain which of initiatives would influence both, the outcome of the exam as well as the final grade, the most. The class size and the sex of the students were used as control variables. The calculations were done via IBM SPSS V24 as well as AMOS V23.

\section{Results}

The results of the path model are mostly matching the expectations laid out in section 2 and the full model is quite good in regard to the final grade (adjusted $\mathrm{R}^{2}=0.451$ ). However, it has to be stated that the influence of extensive supporting material - the manual - had to be excluded as it resulted in collinearity in the model. Nonetheless, the results shows that the feedback-based initiatives like homework as well as the group based learning had an influence on the outcome. These results are not completely matching literature based assumptions: Bigger project groups produce significantly $(\mathrm{p}<0.05)$ worse results in the course than smaller ones. This may indicate that weaker individuals in groups are not getting better results when getting the chance to tackle problems collaboratively. When it comes to mandatory homework, a positive impact on the performance can be seen for the exam. However, students who submit weak homework receive worse final grades, as it is part of the overall grading scheme. By looking at the supporting structure, both, group tutorials as well as video tutorials, had the tendency $(p<0.10)$ to negatively affect student performance in the exam. An explanation for this may be that the availability of these materials lead students to be less motivated to engage with the course material on their own. However, the group tutorials show a tendency to have a positive effect on the final grade. Looking at the control variables, it becomes clear that there is no gender effect and the exam performance correlates strongly with the final grade. However, bigger classes have a tendency to perform better. A potential explanation may be, that bigger classes increase the chance of well performing students offering advice to weaker ones. However, this would be competing with the assessment of the group related learning stated before. 


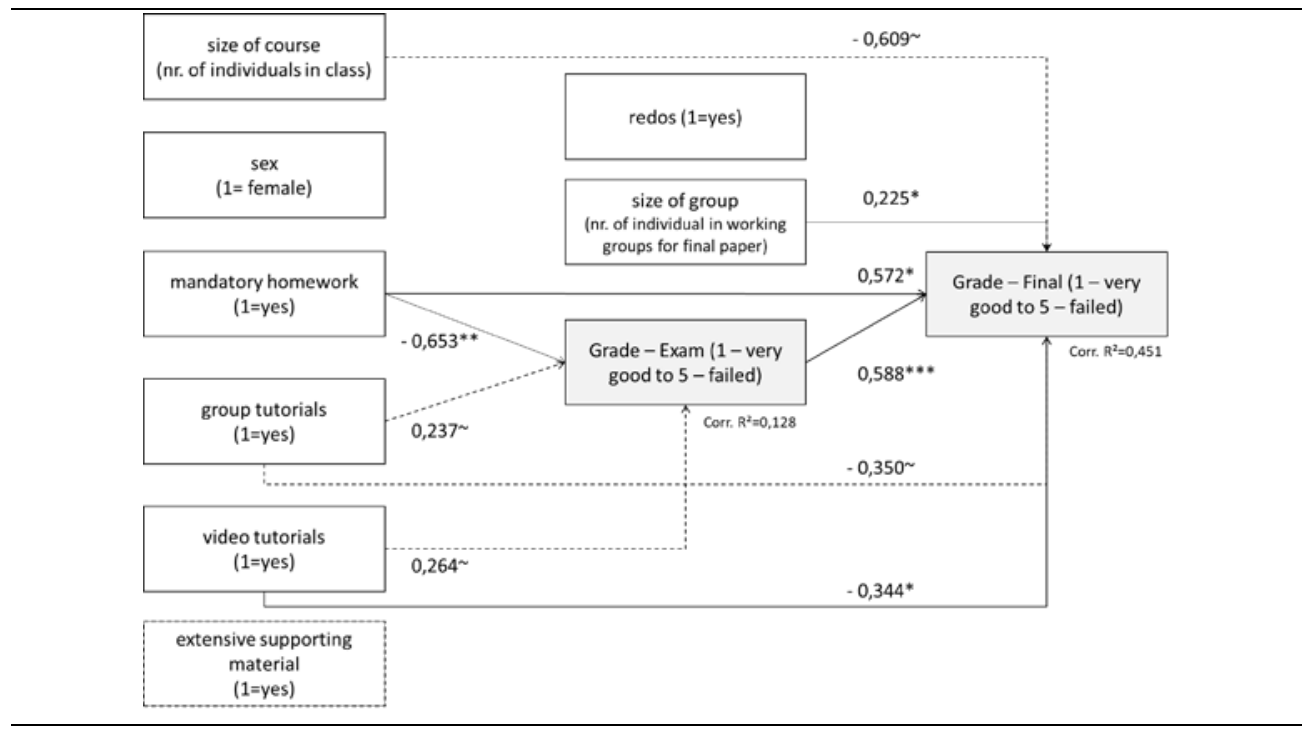

Figure 1. Path model based on linear regression models, arrows indicate direction of influence. Reported effects are based on standardized Beta coefficients ( $n=145$, $(\sim p<0.1 ; * p<0.05 ; * * p<0.01 ; * * * p<0.001))$

\section{Conclusion}

As quantitative data is becoming deeper and deeper ingrained into our daily lives, the need to confront and discuss those numbers, will be a more common part of typical jobs for social scientists. When it comes to teaching empirical methods in social sciences, lecturers and professors have to adapt to this as well, if they want to improve the learning outcomes of students.

Despite the promising results provided in section 4, the study has several limitations. Those are mostly tied to the resources available at the department. It was impossible to assess the performance of all students in the program and not all procedures could be tested in unison. Additionally, student performance was only measured via grades, which are an abstract form of indicating knowledge gains. Nevertheless, the results of the case study make it clear, that a mix of feedback, as well as support driven factors, are influencing student performance in quantitative methods classes. Video tutorials to support students and group tutorials for discussions of specific problems are valuable tools increasing student performance. When it comes to more feedback orientated structures, the model illustrated that homework improves exam performance and thus is advantageous to improve the most commonly needed skills. 
How can you measure which support systems really work to improve students learning in your class?

\section{References}

Ayres, P. (2006). Impact of reducing intrinsic cognitive load on learning in a mathematical domain. Applied Cognitive Psychology: The Official Journal of the Society for Applied Research in Memory and Cognition, 20(3), 287-298. https://doi.org/10.1002/acp.1245.

Baharun, N. \& Porter, A. L. (2012). A web-based learning support to improve students' learning of statistics. 1st ISM International Statistical Conference (359-367).

Carter, J., Brown, M., \& Sumpson, K. (2017). From the Classroom to the workplace: how social science students are doing data analysis for real. Statistics Education Research Journal, 16 (1), 80-101. Retrieved from: http://e-space.mmu.ac.uk/id/eprint/618709.

Cooper, H. (1989). Synthesis of research on homework. Educational leadership, 47(3), 8591.

Cooper, H., Robinson, J. C., \& Patall, E. A. (2006). Does Homework Improve Academic Achievement? A Synthesis of Research, 1987-2003. Review of Educational Research, 76(1), 1-62. doi: https://doi.org/10.3102/00346543076001001.

Couldry, N., \& Mejias, U. A. (2018). Data Colonialism: Rethinking Big Data’s Relation to the Contemporary Subject. Television \& New Media - online first.

Finn, J. D., \& Zimmer, K. S. (2012). Student engagement: What is it? Why does it matter?. In Handbook of research on student engagement (pp. 97-131). Springer, Boston, MA.

Kay, R., \& Kletskin, I. (2012). Evaluating the use of problem-based video podcasts to teach mathematics in higher education. Computers \& Education, 59(2), 619-627.

Kuh, G. D., \& Hu, S. (2001). The effects of student-faculty interaction in the 1990s. The review of higher education, 24(3), 309-332. doi: 10.1353/rhe.2001.0005.

Lycett, M. (2013) 'Datafication': making sense of (big) data in a complex world. European Journal of Information Systems, 22:4, 381-386. doi: 10.1057/ejis.2013.10.

Mayer, R. E., Mathias, A., \& Wetzell, K. (2002). Fostering understanding of multimedia messages through pre-training: Evidence for a two-stage theory of mental model construction. Journal of Experimental Psychology: Applied, 8(3), 147-154.

Michaelsen, L. K., \& Sweet, M. (2008). The essential elements of team-based learning. New directions for teaching and learning, 2008(116), 7-27.

Nardi, P. M. (2018). Doing survey research: A guide to quantitative methods. Routledge.

OECD (2016), Skills Matter: Further Results from the Survey of Adult Skills. Paris: OECD Publishing. doi: https://doi.org/10.1787/9789264258051-en.

Prandner, D. \& Moosbrugger, R. (2018). Who is even studying journalism to become a journalist?. Proceedings of the International Conference on Higher Education Advances, 4, 629-637. DOI: http://dx.doi.org/10.4995/HEAd18.2018.8047

Winch, J. K., \& Cahn, E. S. (2015). Improving student performance in a management science course with supplemental tutorial videos. Journal of Education for Business, 90(7), 402409. doi: https://doi.org/10.1080/08832323.2015.1081865.

Zeidner, M. (1991). Statistics and Mathematics Anxiety in Social Science Students: Some Interesting Parallels. British Journal of Educational Psychology, 61(3), 319-328. 